TITLE:

\title{
A Rival Yesterday is a Friend Today - A Grand Political Drama in the Forest-
}

$\operatorname{AUTHOR}(\mathrm{S})$ :

Hosaka, Kazuhiko

CITATION:

Hosaka, Kazuhiko. A Rival Yesterday is a Friend Today - A Grand Political Drama in the Forest-. Pan Africa News 1995, 2(2): 10-11

ISSUE DATE:

1995-10

URL:

http://hdl.handle.net/2433/143323

RIGHT:

Copyright (c) Pan Africa News. 


\title{
A RIVAL YESTERDAY IS A FRIEND TODAY
}

\author{
--A Grand Political Drama in the Forest--
}

"Ntologi pant-grunted to Nsaba." Pant-grunts are uttered only by a subordinate individual towards a dominant one, for example when greeting. When I heard this news, I felt as if the languishing monarch of a superpower had been overthrown by a coup d'état at last. Indeed, it would be no exaggeration to say that Ntologi has made modern history in M Group!

\section{Ntologi's First Fall from Power}

It was in July, 1979 that Ntologi first took power. He was large but young at approximately age 24 at the time. Successive rivals did not even dare challenge his alpha status.

Kalunde, about 9 years younger than Ntologi, had been beta male since 1987. In February 1991, he accomplished what others had been unable to do for nearly 12 years. According to $\mathrm{M}$. Hamai and $\mathrm{M}$. Bunengwa, Kalunde succeeded in forming a coalition with Nsaba (10 years younger than Kalunde but a huge adult male) and ostracized his great rival at last.

Ntologi, however, did not allow himself to be subordinate to any other (i.e. did not pant-grunt) but began to avoid meeting with any prime adult male. As a result, he had to stay out of the male cluster where most social interactions among adult males took place, forming and maintaining their social bonds. All he could do was to wander alone inside $M$ group's range. His situation seemed to resemble the fate of Kajugi, his predecessor, who was presumed dead after a few years of such a solitary existense.

Kalunde proceeded to the next step and managed to gain alpha status. It was, however, not easy for him to confirm it since there were still several vigorous males that might challenge him. Finally the following triadic balance of power brought favorable results for Kalunde. Nsaba, an ally at the time of rebellion against Ntologi, became Kalunde's most threatening rival. Another influential male, Shike (6 years younger than Kalunde) was very energetic, fequently bluffing others through charging displays. Interestingly enough Nsaba was still quite submissive to Shike while he was not very afraid of Kalunde. On the other hand, Shike feared Kalunde but could easily attack Nsaba. Therefore, Kalunde had two options: he had only to choose either Shike or Nsaba as a coalition partner in order to prevent the other from bluffing. This could be considered an instance of what we call an "opportunistic coalition strategy" unique to adult male chimpanzees.

It was during this period that I reached Mahale for the first time. Kalunde managed to play his role as alpha male. He was the individual pant-grunted to most frequently, able to bluff all others. What to me seemed to be his most impressive demonstration, however, was that he could control noisy meat-eating episodes in the same manner as Ntologi had, sharing meat with old males such as Bakali and some females.

\section{Ntologi Retrieves his Status}

Kalunde's tenure was fragile because it had been maintained by the existence of two rivals. In the beginning of December 1991 Shike suffered from a fatal illness and could not follow as the others ranged. Soon after the political situation changed and Nsaba began to annoy Kalunde through persistent challenges. Kalunde tried to exploit another coalition strategy but in vain. He still managed to control a few meat-eating episodes because others supported him against Nsaba who tried to take meat. However, most chimps had perhaps already realized that Nsaba was about to outrank Kalunde, who displayed a cowardly grin each time Nsaba came bluffing.

At the beginning of January 1992 while it was not certain who was alpha male, the male cluster suddenly dispersed as if the political turmoil had halted and both Kalunde and Nsaba began to range alone.

Ntologi did not miss this chance. Although he 
could not see the political change itself, he might have caught enough information from the vocalizations of others, at least enough to deduce the social relationships among the adult males. At that time he was no longer alone but had a companion, Jilba (12 years younger than Kalunde). Jilba had also been ostracized through a gang attack initiated by Kalunde, due to his defiant attitude against that male.

Once I observed Ntologi and Jilba within earshot of other members of $M$ group. During the dispersal of the adult males, Ntologi and Jilba were occasionally lucky enough to range with some old friends. First they found Musa, an old male, and the three walked together for two days. Then they found Bakali. On January 13, 1992, I accidentally found Kalunde repeating noisy, frightened-sounding. "wraa" calls. Then I heard a pant hoot about 300 meters northwards from the direction to which Kalunde had fixed his eyes. Later I heard that Ntologi and Bakali, an old male, produced a chorus of pant-hoots there. Therefore it is reasonable that Kalunde had known who was calling and that Ntologi also noticed Kalunde's fall from power.

On January 20,1992, Ntologi abruptly appeared in a large party. Kalunde and Nsaba also were there. The conflict between Kalunde and Nsaba had been blown off. Ntologi returned as alpha male! He celebrated his own reinstatement by holding a spectacular meat-eating party. His return was marked by a drastic change in relations with Kalunde, the very rival who had ostracized him. They were friends, just as if they had been so for a long time. For example, on the day Ntologi returned Kalunde obtained some meat from him. Very often they mutually groomed. During some grooming episodes they even kissed each other with mouths fully open and then this excitement was followed by play, a scene which previously could not have been imagined. I interpreted it as a process of reconciliation that had to be carried out to confirm their new relationship. Both Kalunde and Nsaba now pantgrunted to Ntologi. Other members in $\mathrm{M}$ group also greeted him with pant-grunts.

\section{Stable Triangle}

Ntologi's tenure continued for the following three years and three months. This might have been possible because of the stable triangle of Ntologi, Nsaba, and Kalunde. The three ranked in order of dominance (from the top): Ntologi, Nsaba, and Kalunde. However, the alliance between Ntologi and Kalunde against Nsaba was in fact what determined their real relationships. Ntologi had to separate Kalunde and Nsaba so as to suppress any renewal of their alliance. Kalunde also needed assistance from Ntologi since he still continued in a tense rivalry with Nsaba, as was sometimes explicit during the Ntologi's absence.

Ntologi engaged in a variety of intimate interactions with Kalunde as stated but at the same time behaved harshly towards Nsaba. In fact, Ntologi even refused to be groomed by Nsaba. Kalunde adopted a more complex and more ambivalent strategy. That is, he initiated many cooperative attacks against Nsaba, but he also sometimes walked with Nsaba apart from Ntologi, exchanged grooming and joined in a chorus of pant-hoots with him. He seemed to be displaying to Ntologi his readiness to change his coalition partner. In fact, in some cases Kalunde initiated cooperative attacks with Nsaba against Ntologi. However, he always betrayed Nsaba at the end of such cases and quickly restored intimate relations with Ntologi through grooming. Maybe he no longer had any intention to ostracize Ntologi again because it would inevitably be followed by fierce conflicts with Nsaba.

Nsaba could never alone challenge Ntologi as long as this stable triangle was in effect. In 1993 when I visited Mahale again, this alliance still worked as the core of the male cluster. Nsaba had not yet challenged Ntologi even though the alpha male had reached the age of 38 .

According to a recent letter by Professor Nishida who is now at Mahale, Ntologi came back to the group but this time as a low-ranking male. We can expect detailed news from him in the next issue. I am intrigued by a question: "Why did such a stable triangle collapse?"

Kazuhiko Hosaka Laboratory of Human Evolution Studies Kyoto University 